\title{
Creating a Geodatabase for Tourism Research in the Sultanate of Oman
}

\author{
Marius HERRMANN ${ }^{1}$ and Adrijana $\mathrm{CAR}^{2}$ \\ ${ }^{1}$ Dept. of Geography and Geology, University of Salzburg/Austria · marius.herrmann@stud.sbg.ac.at \\ ${ }^{2}$ German University of Technology in Oman, Maskat/Sultanate of Oman
}

This contribution was double-blind reviewed as extended abstract.

\begin{abstract}
This paper presents a way of designing and populating a spatial database for tourism research in the Sultanate of Oman. The recent rapid development of tourism in the Sultanate of Oman has created a strong need for research in this field to which GIS can contribute through analysis, modelling and forecasting (MCADAM 1999).

Tourism is a multidisciplinary field for which a database allows integration of quantitative and qualitative data. Here the database is populated from data sources that are freely available on the internet and provide a good quality of geodata for the Sultanate of Oman. A key aspect of this paper presents a spatial model of a Tourism Product. This model is explained, implemented and exemplified for Tourism Products in south Oman.

An online metadatabase helps to document all data and related sources and provides an interface for communicating and sharing various kinds of data within the research project team. With the results from this pilot project tourism-related questions can be answered using GIS and structures of tourism in the Sultanate of Oman can further be analysed and visualized in an ongoing research project.
\end{abstract}

\section{Introduction}

Tourism was identified as one of the economy sectors to contribute to the diversification of Oman's economy and reduce the dependency on oil revenues (WINCKLER 2007). For this reason a Ministry of Tourism was established in 2004 and many tourism projects are currently being conducted all over the Sultanate of Oman (MINISTRY OF TOURISM OMAN n. d.). As such a development creates a variety of problems, research in tourism is needed to analyse and model implications of tourism development. Given the spatial nature of tourism, inclusion of GIS can bring significant added value to tourism research (BAHAIRE \& ELLIOTT-WHite 1999, RitCHIE et al. 2005).

The aim of our project is creating a geodatabase for Oman that can be used in a research project focusing on tourism and the socio-economic development of local communities in Oman on a regional level. This research project is multidisciplinary, with tourism researches having background from anthropology, business administration, economics, geography, sociology and GIScience. Bringing all these disciplines together is possible 
because we use GIS as a communication tool (SUI \& GOODCHILD 2003). The geodatabase is designed in a way that all these disciplines can profit from the use of GIS by integrating quantitative as well as qualitative data. This enables researchers to add, compare, discuss and share spatial and non-spatial data.

\section{Database Design and Implementation}

The main idea for the database is to bring two kinds of objects together: Basic Features describing Oman in form of general geodata and Tourism Features specially related to the field of tourism. The first category contains data describing the topography - physical landscape, infrastructure, administrative units, settlements, and parcels. Tourism Features consist of Tourism Attractions and Tourism Products.

The project data is physically stored in an ESRI File Geodatabase. An online metadatabase (comet.gutech.edu.om) provides all researchers with the metadata about the used datasets. The metadatabase supports critical thinking and data quality assurance within the research project, because the data used in the project is traceable and can be discussed within the research team. This metadatabase also facilitates sharing of data to enable communication amongst researchers. The Basic Features for the geodatabase were collected from openly available sources throughout the internet (Table 1).

Table 1: Overview on data sources for Basic Features for Oman

\begin{tabular}{|l|l|l|}
\hline Datasource & Datatype & URL \\
\hline OpenStreetMap & $\begin{array}{l}\text { Roads, POI, } \\
\text { Settlements }\end{array}$ & http://downloads.cloudmade.com \\
\hline GADM & Administrative Units & http://www.gadm.org/country \\
\hline DIVA GIS & Places and Placenames & http://www.diva-gis.org/datadown \\
\hline ESA GlobCover & Land Cover & http://due.esrin.esa.int/globcover/ \\
\hline SRTM & DEM (90m) & http://srtm.csi.cgiar.org/ \\
\hline ASTER & DEM (30m) & http://gdem.ersdac.jspacesystems.or.jp/index.jsp \\
\hline Natural Earth & Hydrography & http://www.naturalearthdata.com \\
\hline Geonames & Places, Placenames & http://download.geonames.org/export/OM.zip \\
\hline
\end{tabular}

While the Basic Features for Oman can be acquired from the sources mentioned in Table 1, obtaining tourism specific features is more difficult. The Tourist Attractions are provided in form of point data from MINISTRY OF TOURISM OMAN (n.d.) and follow their classification. The essential part is describing a Tourism Product in spatial terms. In the following we introduce a model of a Tourism Product that is not only limited to Oman but is also applicable to other geographical regions.

\section{Model of a Tourism Product}

According to SMITH (1994) a Tourism Product is always located at a physical plant (location) that is frequented by tourists. But the physical plant insufficiently describes why 
tourists visit a Tourism Product. Additional elements, like services and hospitality, are necessary to make a physical plant a Tourism Product. These are described as six " $A$ ' $s$ " of tourism in the approach by BUHALIS (2000) or five " $A$ ' $s$ " as identified by TOURISM WA (2009). These two approaches have four elements in common: attraction, access, accommodation and amenity. We define these as necessary to describe a Tourism Product in addition to the physical plant and thus included them in our Tourism Product model. A concept describing local communities will be added to the model to allow focus on socio economic development of local communities in a regional approach. All these ideas lead to the model shown in figure 1.

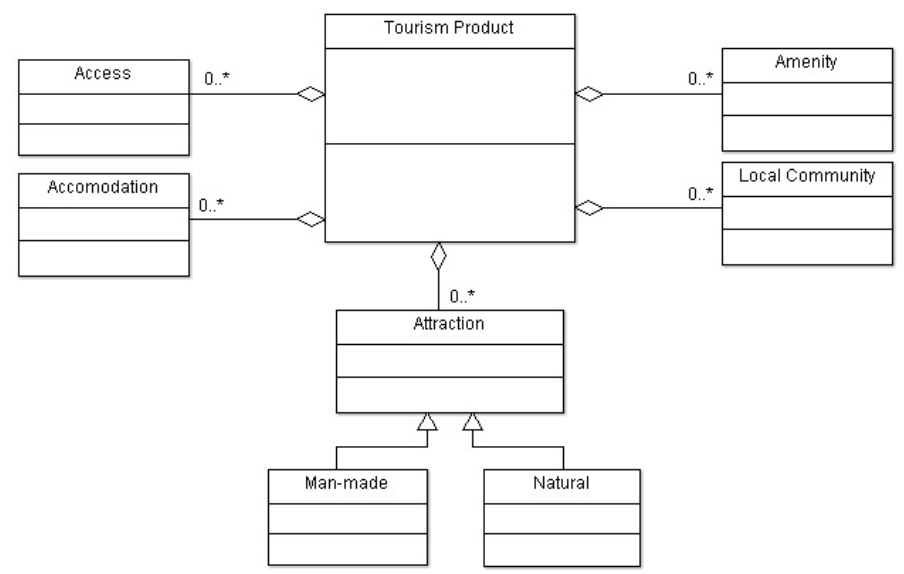

Fig. 1:

Model of

Tourism Product

The Tourism Product in this model is conceptualised as follows: it is a polygon surrounding the area that is frequented by tourists. Its spatial boundary can be determined based on qualitative knowledge from field work, digitalized from satellite images or orthophotos, or it can be derived from the basic (geo)data. An example for this is extracting a wadi based on elevation, a pour point and an elevation threshold using spatial analysis tools or extracting sand dunes form land cover data. The model is independent from the method that is used and is also open for working with different spatial boundaries for a Tourism Product.

Gunn \& Var (2002, p. 137) identify two zones around a Tourism Product. An "Inviolate Belt" that sets the Tourism Product into context within its surrounding environment and a "Zone of Closure" where all elements associated with a Tourism Product are located. Based on this we are able to create a zone around the core of each Tourism Product to identify the elements - access, accommodation, attraction, amenity, and local community associated with it.

In physical terms the five elements associated with a Tourism Product can be implemented as many-to-many relations, where objects from a data source of the Basic Features are linked to a Tourism Product. In this relation one Tourism Product can have several of the five elements associated with it while each of the elements can also be linked to several Tourism Products. The elements belonging to a certain Tourism Product are the ones intersecting the "Zone of Closure" (Gunn \& Var 2002, p. 137). This zone can be implemented as a buffer zone around the respective Tourism Products. The associated elements can also be defined by manual selection, for example based on qualitative aspects, or 
employing a Public Participation GIS (PPGIS). Summing up, the Tourism Product is a complex object, where not only the polygon of the core area of a Tourism Product is stored, but also the relations to the five associated elements - attraction, access, accommodation, amenity and local community.

\section{$4 \quad$ Implementation}

Figure 3 gives an example for the use of this model for the Salalah region, south Oman. Four Tourism Products were identified: the city of Salalah, the villages of Taqa and Mirbat, and the Wadi Darbat. Around these Tourism Products the two zones are visualized as two buffer zones (GUNN \& VAR 2002). The buffer distance of the two zones is bigger for natural Tourism Products like the wadi than for villages (see figure 2). The buffer distances for every Tourism Product can be determined individually, for example based on field work.

The grey points are Points of Interest (POI) from OpenStreetMap data (figure 2, left). The POIs include services that are important for tourists such as restaurants, cafes, bars, petrol stations, ATMs, shops, banks and hospitals. The points associated with the Tourism Products are the respective amenities visualized in darker colour (figure 2, right). One can now identify, search or query the amenities of the Tourism Products. In addition, new quantitative or qualitative attributes can be added to the relation between POI and Tourism Product to describe objects as amenities for the Tourism Products. This is an example application of our model. This model is the starting point for further geospatial analysis on Tourism Products.
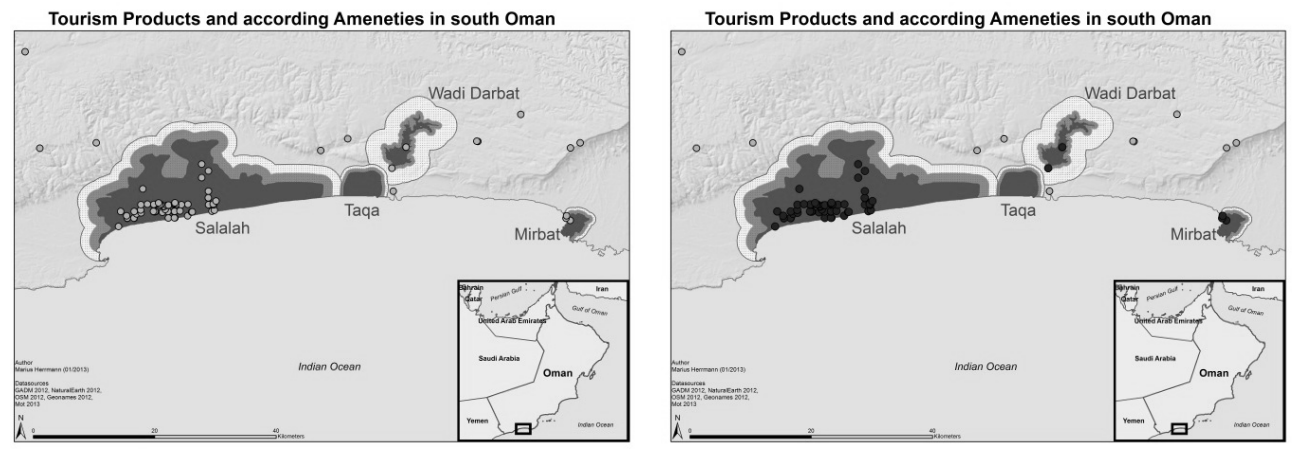

Fig. 3: POI and Amenities of Tourism Products in south Oman

\section{Conclusion and Outlook}

The presented geodatabase facilitates current and future research in the tourism sector of the Sultanate of Oman. The combination of Basic Features (mainly topographic) and special tourism features allows using GIS for a variety of tasks such as spatial-temporal analysis and visualization of tourism in Oman. The current model can be expanded to 
further support monitoring of tourism development as well as modelling and forecasting of future impacts of tourism projects. With the developed model a Tourism Product can be described and implemented spatially. The presented model is applicable to Oman and other regions. The metadatabase facilitates sharing of data used in the project and documents the implementation of the Tourism Products. Given that the developed geodatabase allows integration of quantitative and qualitative data and the Tourism Product model is open for qualitative approaches, this geodatabase allows a GIS to be used as a communication tool within the ongoing research in the multidisciplinary field of tourism.

\section{References}

BAhaire, T. \& M. Elliot-White (1999), The Application of Geographical Information Systems (GIS) in Sustainable Tourism Planning: A Review. Journal of Sustainable Tourism, 7 (2), 159-174.

Buhalis, D. (2000), Marketing The Competitive Destination Of The Future. Tourism Management, 21 (1), 97-116.

GunN, C. A. \& VAR, T. (2002), Tourism Planning. Basics, Concepts, Cases. New York, Taylor and Francis.

MCADAM, D. (1999), The Value and Scope of Geographical Information Systems in Tourism Management. Journal of Sustainable Tourism, 7 (1), 77-92.

MinistRy OF TOURISM OMAN (n. d.), Tourism Strategy Executive Summary. Muscat.

Ritchie, B. W., Burns, P. \& Palmer, C. (Eds.) (2005), Tourism Research Methods: Integrating Theory with Practice. Wallingford, Cabi Publishing.

Smith, S. L. J. (1994), The Tourism Product. Annals of Tourism Research, 23 (3), 582-595.

Sui D. Z. \& GoodchiLd, M. F. (2003), A Tetradic Analysis of GIS and Society Using Mcluhan's Law of the Media. The Canadian Geographer, 47 (1), 5-17.

TOURISM WA (2009), Five A's Of Tourism.

http://www.tourism.wa.gov.au/jumpstartguide/pdf/Quickstart_five $\% 20 \mathrm{~A} \% 27 \mathrm{~s} \% 20 \mathrm{of} \% 2$ 0TourismLOW.pdf (03.11.2012).

WINCKLER, O. (2007), The Birth Of Oman's Tourism Industry. Tourism Professional Paper, $55(2), 221-234$. 